\title{
Development and Characterization of Cross-Linked Poly(acrylic acid) Hydrogel Containing Drug by Radiation-Based Techniques
}

\author{
Jin-Oh Jeong a,b, $\uparrow$, Jae Baik ${ }^{\text {a, }}+$, Sung-Jun An ${ }^{\text {a }}$, Sung-In Jeong a , Jae-Young Lee ${ }^{\text {, }}$ \\ Youn-Mook Lim ${ }^{\text {a, }}$, Jong-Seok Park ${ }^{\text {a, * }}$ \\ aAdvanced Radiation Technology Institute, Korea Atomic Energy Research Institute, 1266 Sinjeong- \\ dong Jeongeup-si Jeollabuk-do, 580-185, Rep. of Korea \\ ${ }^{b}$ School of Materials Science and Engineering, Gwangju Institute of Science and Technology (GIST), \\ Gwangju 61005, Republic of Korea \\ ${ }^{c}$ Department of Organic Materials and Fibers Engineering, Chonbuk National University, Jeongju 561- \\ 756, Rep. of Korea \\ $\uparrow$ These authors contributed equally to this work \\ * To whom correspondence should be addressed
}

Abstract: Poly(acrylic acid) (PAAc) hydrogels possess good bioadhesive properties and allow enhanced penetration of drugs. In addition, it is possible to localize the absorption site of the drug in the hydrogel and increase the drug residence time. As opposed to other cross-linking processes radiation-induced polymer cross-linking can be easily and rapidly carried out without the use of cross-linking agents and other chemical additives. In this study, we fabricated metronidazole (MD) containing PAAc hydrogel (MD/PAAc) with different MD contents ( 0.1 , $0.25,0.5 \mathrm{wt} \%)$ using varying radiation doses $(25,50,75 \mathrm{kGy})$ by gamma-irradiation. The physical and thermal properties were determined by gel content analysis, swelling ratio measurements, compressive strength measurements, differential scanning calorimetery, and thermogravimetric analysis. The properties of the hydrogel degraded due to the crystalline nature of MD. The properties of the hydrogel degraded due to the crystalline nature of MD. Cumulative release observed after $50 \mathrm{~min}$ in the case of $0.5 \mathrm{MD} / \mathrm{PAAc}$ and $0.1 \mathrm{MD} / \mathrm{PAAc}$ was $50 \%$ and $10 \%$, respectively. Our findings suggest that MD/PAAc could be a suitable drug delivery carrier for use with radiation-based techniques.

Keywords : poly(acrylic acid); metronidazole; hydrogel; crosslinking; radiation 


\section{Introduction}

A hydrogel is defined as a three-dimensional polymeric network that can be contained in water or body fluids [1]. Hydrogels have been widely used in biological applications such as wound dressings, adhesion prevention films, and contact lenses because of their marked similarity of human tissue, excellent biocompatibility, and controllable properties [2-4]. In addition, hydrogels retain stable volume in the body owing to the formation of stable structures that show little fluidity under the application of external forces. Hydrogels are fabricated by physical and chemical cross-linking processes $[5,6]$. Physical crosslinking is achieved by the formation of ionic bonds, hydrogen bonds, crystallization between the polymer chains, or freezing/thawing method. In the freezing/thawing method, cross-linking is achieved by the formation of crystallites in the polymer-rich domain between water and the polymer chain during repeated freeze/thaw cycles. However, the inherent disadvantage is the long process time of 3 or 4 days [7]. In contrast, chemical cross-linking processes are fast in nature. In this case, cross-links are formed by chemical and radical reactions. Irradiation of polymer solutions results in polymer radicals, which combine through covalent bonds to form insoluble hydrogels. [8].

In the case of radiation-induced cross-linking, cross links are formed at the carbon atom of the $\mathrm{C}-\mathrm{C}$ bond in the polyvinyl polymer, because one or more hydrogen atoms could be attached to the carbon atom. The radiation cross-linking method has many advantages: cross-linking agents are not required $[9,10]$; no residual toxic substances are found in the hydrogel; hydrogels having diverse properties can be fabricated by simply controlling radiation dose, polymer concentration, and atmosphere of radiation exposure [11-13].

Hydrogels are typically composed of polymers such as natural polymers (e.g., collagen, gelatin, hyaluronic acid, and chitosan) and synthetic polymers (e.g., poly(acrylic acid) (PAAc), 
1 polyethylene oxide (PEO), and poly(vinyl alcohol) (PVA)) $[8,9,14,15]$. The synthetic polymers

2 allow for a higher degree swelling, and impart superior mechanical properties and adhesion strength to the hydrogels as compared to those in the case of natural polymers. For example, PAAc hydrogels show good adhesion strength and are used in bioadhesive drug delivery systems $[16,17]$. PAAc is a hydrophilic and a highly absorbent polymer that has been widely applied to biomaterials due to its high solubility and biodegradability [5]. PAAc hydrogels have been widely used as drug carriers because of their good bioadhesive properties and enhanced drug penetration. It is possible to localize the absorption site of the drug in the PAAc hydrogel and increase the drug residence time [18].

Metronidazole (MD) is a nitroimidazole compound that has been widely used for treating infections caused by anaerobic bacteria and otitis media. The nitro group of MD is activated by nitroreductases such as ferredoxin in the body. High antibacterial property is indicated by disturbed DNA division and nucleic acid synthesis, which can be due to the destruction of the helical structure of the bacterial DNA [19].

In this study, PAAc and MD mixtures were exposed to $\gamma$-radiations, and MD containing PAAc hydrogels were verified by gel content analysis, swelling ratio measurements, attenuated total reflection Fourier transform infrared spectroscopy (ATR-FTIR), differential scanning calorimetry (DSC), thermogravimetric analysis (TGA), compressive strength tests, and cumulative release of MD analysis. Past studies have reported the fabrication of hydrogels under to $\gamma$-irradiation. This study focuses on the MD containing PAAc hydrogel and can reveal a promising approach for the development of radiation cross-linking processes. 


\section{2. Experimental}

2

3

4

5

6

16

17

18

19

\subsection{Materials}

Poly(acrylic acid) (PAAc, molecular weight $=100,000)$ was purchased from Waco Pure Chemical Industries, Ltd (Osaka, Japan). Metronidazole (MD) was obtained from SigmaAldrich (St. Louis, MO, USA). All other reagents and solvents were of analytical grade and used as received.

\subsection{Preparation of metronidazole containing poly(acrylic acid) film using $\gamma$-irradiation}

PAAc was dissolved in distilled water using a magnetic stirrer to a final concentration of 7 wt $\%$. MD $(0.1,0.25,0.5$, and $1 \mathrm{wt} \%)$ was dissolved in the PAAc solution by using a shaking incubator at $50{ }^{\circ} \mathrm{C}$ at $100 \mathrm{rpm}$ until perfect dissolution, under dark conditions. The MD containing PAAc solution was irradiated using a ${ }^{60} \mathrm{Co}$ source (ACEL type C-1882, Korea Atomic Energy Research Institute) with different radiation doses of 25, 50, and $75 \mathrm{kGy}$ (10 $\mathrm{kGy} / \mathrm{h}$ ) to prepare the MD containing PAAc hydrogel film (MD/PAAc). The general schematic and abbreviated MD/PAAc samples are shown in Figure 1 and Table 1.

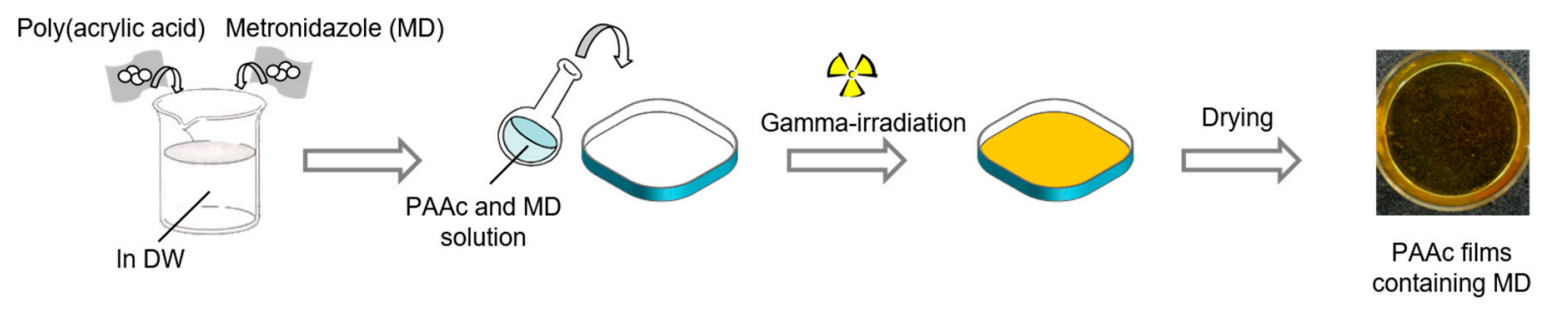

Figure 1. Schematic diagrams of MD containing PAAc hydrogel films using $\gamma$-irradiation. 
Table 1. Characteristics of MD containing PAAc hydrogel films at different radiation 3 doses

\begin{tabular}{cccc}
\hline Sample & PAAc content $(\mathrm{wt} \%)$ & MD content (wt $\%)$ & Radiation dose (kGy) \\
\hline PAAc & 7 & 0 & 0 \\
MD/PAAc & 7 & 1 & 0 \\
MD/PAAc25 & 7 & 1 & 25 \\
MD/PAAc50 & 7 & 1 & 50 \\
MD/PAAc75 & 7 & 1 & 75 \\
0.1 MD/PAAc & 7 & 0.5 & 25 \\
$0.25 \mathrm{MD} /$ PAAc & 7 & 1 & 25 \\
$0.5 \mathrm{MD} /$ PAAc & 7 & 2 & 25 \\
\hline
\end{tabular}

4

6 The thermal properties of MD/PAAc were investigated by DSC analysis (sQ100, TA

7 instrument, New Castle, PA, USA) under nitrogen flow. The analysis was performed at a 8 heating rate $10{ }^{\circ} \mathrm{C} / \mathrm{min}$ from 100 to $180^{\circ} \mathrm{C}$.

\subsection{Thermogravimetric analysis}

Thermogravimetric analyses were performed using a TA Q600 system (TA Instrument, New Castle, PA, USA). $15.0 \mathrm{mg}$ of the MD/PAAc sample was placed in a platinum pan. The analysis was performed at a heating rate $10{ }^{\circ} \mathrm{C} / \mathrm{min}$ from 35 to $600{ }^{\circ} \mathrm{C}$ under nitrogen flow 


\subsection{Determination of gel content}

Prior to gel content measurements, the MD/PAAc samples were dried until they were completely free of water. MD/PAAc test specimens were prepared using an $8 \mathrm{~mm}$ biopsy punch (Integra, USA). The initial weight of the samples was recorded, and the samples were stirred in distilled water for $24 \mathrm{~h}$ at room temperature to remove insoluble components. Then, the MD/PAAc samples were dried and weighed for calculating the gel content. The gel content in the film was determined from the following equation:

$$
\text { Gel content }(\%)=\left(W_{l} / W_{i}\right) \times 100
$$

where $W_{i}$ and $W_{l}$ represent the initial and final weights of the dried samples, respectively.

\subsection{Determination of swelling ratio}

To measure the swelling ratio, the dried film was prepared by an $8 \mathrm{~mm}$ biopsy punch (Integra, USA) and then immersed in distilled water for different time intervals at room temperature, until the equilibrium swelling state was reached. The swelling ratio of the film was determined from the following equation:

$$
\text { Swelling ratio }(\%)=\left[\left(W_{w}-W_{d}\right) / W_{d}\right] \times 100
$$

where $W_{d}$ and $W_{w}$ represent the weights of dry and wet film, respectively.

\subsection{Compressive strength}

The MD/PAAc sample was prepared by using a $12 \mathrm{~mm}$ biopsy punch and then subjected to compressive strength measurements using a texture analyzer (TA-XT2i, Stable Micro Systems Ltd., Godalming, UK) with a load of $50 \mathrm{~N}$ and a working distance of $20 \mathrm{~mm}$ from the punch. The compressive strength was measured under 50\% compression, from the decomposition of the hydrogel film between the plates of the test machine, at a crosshead speed of $5 \mathrm{~mm} / \mathrm{s}$. 


\section{1 \\ 2.8. Attenuated total reflection Fourier transform infrared spectroscopy}

2

3

4

The chemical properties of the MD/PAAc samples were measured using an FTIR instrument in ATR mode (ATR-FTIR, Bruker TEMSOR 37, Bruker AXS. INC., Karlsruhe, Germany) over the range 650 to $4000 \mathrm{~cm}^{-1}$ at a resolution of $6 \mathrm{~cm}^{-1}$ averaged over 64 scans.

\subsection{Release test}

MD/PAAc hydrogels were dried at room temperature. Each dried sample was immersed in phosphate buffered saline(PBS) and incubated in a water bath (BS-21, JEIO TECH, Daejeon, Korea) at $37{ }^{\circ} \mathrm{C}$ for $120 \mathrm{~min}$, with gentle shaking at $50 \mathrm{rpm}$. Samples were acquired at predetermined time intervals $(0,10,20,30,40,50,60$, and $120 \mathrm{~min})$, and the released MD was measured using a UV-Vis spectrophotometer (S-3100, Scinco, Seoul, Korea). The absorbance was recorded at $319 \mathrm{~nm}$.

\subsection{Statistical analysis}

All data were presented as mean standard deviation (SD) for $n=4$. The t-test (Excel, Microsoft) was used to assess the statistical significance of the results $(p<0.05)$.

\section{Results and Discussion}

Under $\gamma$-irradiation, PAAc formed free radicals on the polymer chain [17]. The water molecule formed a hydroxyl radical $(\mathrm{OH} \cdot)$ and a hydrogen radical $(\mathrm{H} \cdot)$. The $\mathrm{C}-\mathrm{H}$ bond of PAAc was broken by the hydroxyl radical $(\mathrm{OH} \cdot)$ to form a free radical on the PAAc chain. The released hydrogen radical $(\mathrm{H} \cdot)$ combined with $\mathrm{H} \cdot$ from water, leading to hydrogen gas evolution. In addition, the free radical of PAAc can cross-link with other PAAc molecules, resulting in the formation of a PAAc hydrogel [22]. The overall reaction mechanism of MD/PAAc is shown in 
1 Figure 2.

2

(1) $\mathrm{H}_{2} \mathrm{O} \stackrel{\text { Gamma-irradiation }}{\longrightarrow} \mathrm{OH}^{\cdot}+\mathrm{H}^{\cdot}+\mathrm{H}_{2}+\mathrm{H}_{2} \mathrm{O}_{2}+\mathrm{H}^{+}{ }_{\text {aq }}+\mathrm{HO}^{-}$aq<smiles>CC(C)(C)CC(C(=O)O)C(C)(C)C</smiles>

Poly(acrylic acid)

(3)<smiles>CC(C)(C)CC(C)(C(=O)O)C(=O)O</smiles>

4

5 Figure 2. Chemical mechanism of MD containing PAAc hydrogel films using $\gamma$-irradiation

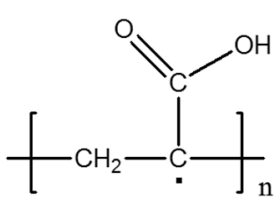

Formed free radical

Combined radical

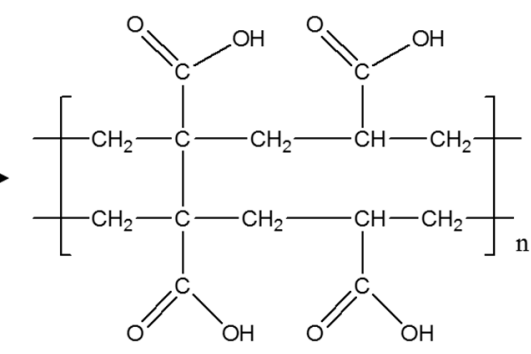

Cross-linked PAAc network 6

$7 \quad$ MD has 4 main physical characteristics: (1) it is difficultly soluble in common solvents; (2) it

8 has a crystalline structure and the crystals are off-white in color; (3) it is temperature-sensitive;

9 and (4) its color is easily changed upon exposure to light $[20,21]$. The color of the MD/PAAc

10 hydrogel films changed to dark yellow with an increase in the radiation dose from 25 to 75

$11 \mathrm{kGy}$, due to prolonged exposure to high-energy $\gamma$-radiation. The optical images and thicknesses

12 of the MD/PAAc films are shown in Figure 3 and Table 2. 


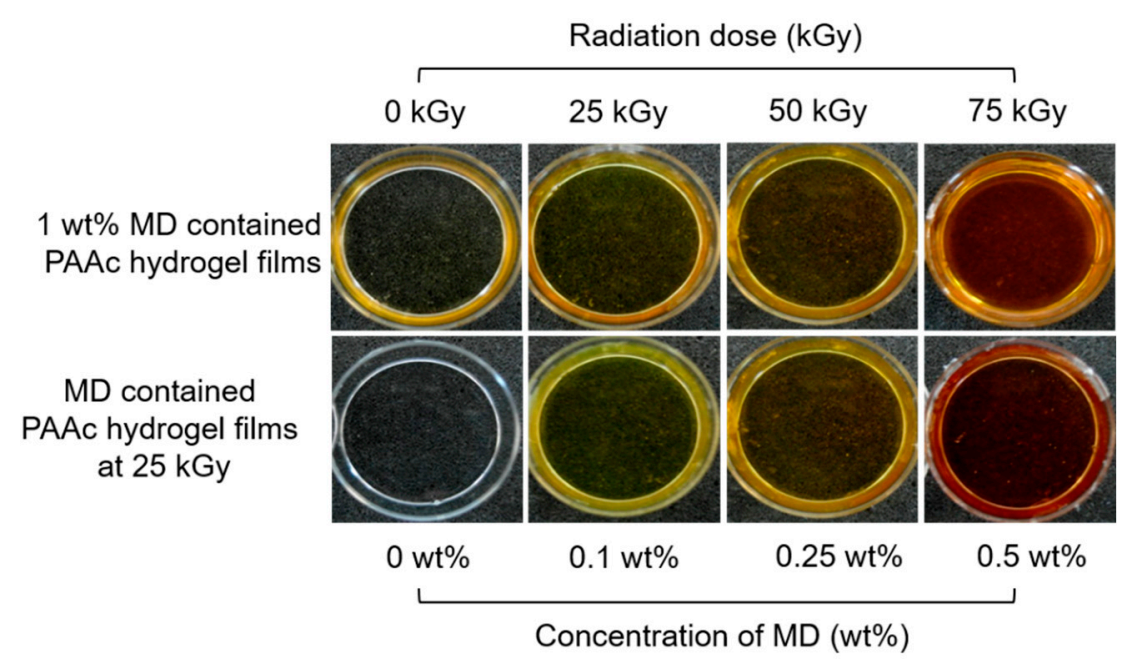

2 Figure 3. Optical images of MD containing PAAc hydrogel films using $\gamma$-irradiation 3

4 Table 2. Thickness of MD containing PAAc hydrogel films at different radiation doses

\begin{tabular}{cc}
\hline Sample & Thickness (mm) \\
\hline MD/PAAc25 & $0.207 \pm 0.030$ \\
MD/PAAc50 & $0.243 \pm 0.047$ \\
MD/PAAc75 & $0.317 \pm 0.029$ \\
$0.1 \mathrm{MD} /$ PAAc & $0.280 \pm 0.052$ \\
$0.25 \mathrm{MD} / \mathrm{PAAc}$ & $0.243 \pm 0.047$ \\
$0.5 \mathrm{MD} / \mathrm{PAAc}$ & $0.277 \pm 0.035$ \\
\hline
\end{tabular}

5

6 The thermal properties of MD/PAAc were confirmed using DSC and TGA data, as shown

7 in Figure 4 and Figure 5. The melting temperature $\left(T_{m}\right)$ of MD/PAAc increased with an increase

8 in $\mathrm{MD}$ content. $\mathrm{T}_{\mathrm{m}}$ of $0.1 \mathrm{MD} / \mathrm{PAAc}, 0.25 \mathrm{MD} / \mathrm{PAAc}$, and $0.5 \mathrm{MD} / \mathrm{PAAc}$ was $132.68,135.33$,

9 and $135.74{ }^{\circ} \mathrm{C}$ respectively, and the difference between these values increased by approximately

$10 \quad 3{ }^{\circ} \mathrm{C}$ after exposure to $\gamma$-radiation. In addition, the latent heat increased with an increase in MD

11 content, suggesting that the high crystallinity of MD, as shown in Table 3. The initial 
1 degradation temperature of MD/PAAc was approximately $60^{\circ} \mathrm{C}$, and further degradation peaks

2 were observed at 210 and $340{ }^{\circ} \mathrm{C}$ owing to the decomposition of MD [22]. The residual amounts

3 of PAAc were $89.91 \%$ and $63.87 \%$ at 210 and $340{ }^{\circ} \mathrm{C}$, respectively. The MD/PAAc content was

$4 \quad 86.67 \%$ and $61.08 \%$ at the same temperatures, and the weight decreased with an increase in the

5 MD content. Furthermore, the remaining amounts of MD/PAAc 75 were $83.71 \%$ and $58.86 \%$,

6 which were lower than that of MD/PAAc, as shown in Table 4. The thermal stability decreased

7 slightly as the radiation dose was increased because MD slightly affects the thermal stability.

(a)

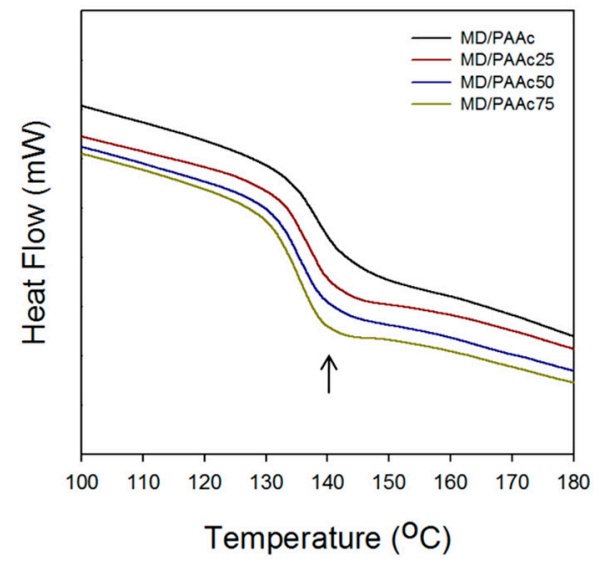

(b)

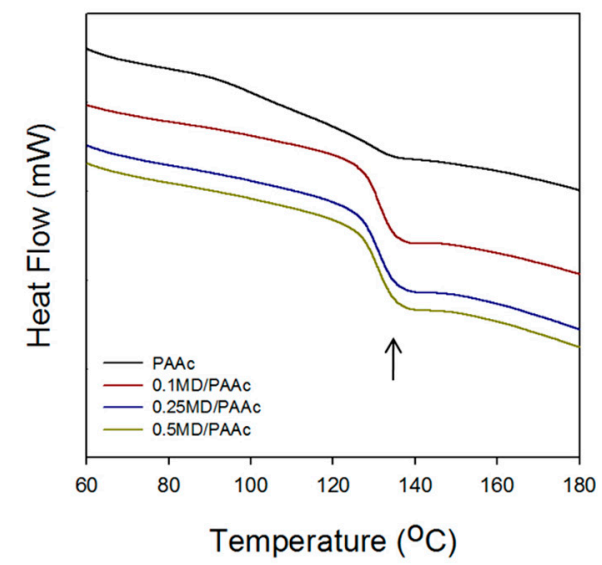

Figure 4. Thermal properties of MD containing PAAc hydrogel films by DSC analysis: (a) MD containing PAAc hydrogel films with different contents of MD $(0,0.1,0.25$, and $0.5 \mathrm{wt} \%)$ and radiation doses at $25 \mathrm{kGy}$, (b) $1 \mathrm{wt} \% \mathrm{MD}$ containing PAAc hydrogel films with different radiation doses $(0,25,50$, and $75 \mathrm{kGy})$. 


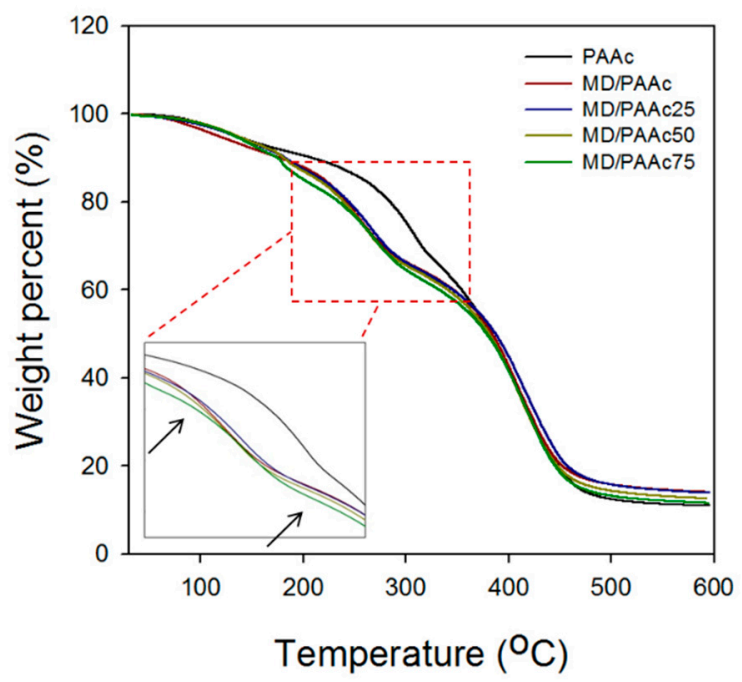

Figure 5. Thermal properties of $1 \mathrm{wt} \%$ MD containing PAAc films using TGA, at different radiation doses of $0,25,50$, and $75 \mathrm{kGy}$.

Table 3. Melting point and latent heat of MD containing PAAc hydrogel films with different radiation doses, as determined by DSC

\begin{tabular}{lcc}
\hline & $\operatorname{Tm}\left({ }^{\circ} \mathrm{C}\right)$ & Latent heat $(\mathrm{J} / \mathrm{g})$ \\
\hline $0.1 \mathrm{MD} / \mathrm{PAAc}$ & 132.68 & 2.68 \\
$0.25 \mathrm{MD} / \mathrm{PAAc}$ & 135.33 & 3.36 \\
$0.5 \mathrm{MD} / \mathrm{PAAc}$ & 135.74 & 3.86 \\
MD/PAAc25 & 142.94 & 4.11 \\
MD/PAAc50 & 141.47 & 3.57 \\
MD/PAAc75 & 140.19 & 2.75 \\
\hline
\end{tabular}

7

8

9 
Table 4. Residual amounts $\left(210{ }^{\circ} \mathrm{C}\right.$ and $\left.340{ }^{\circ} \mathrm{C}\right)$ of MD containing PAAc hydrogel films at different radiation doses determined by TGA.

\begin{tabular}{ccc}
\hline Sample & $210^{\circ} \mathrm{C}$ & $340{ }^{\circ} \mathrm{C}$ \\
\hline PAAc & 89.91 & 63.87 \\
MD/PAAc & 86.67 & 61.08 \\
MD/PAAc25 & 86.13 & 60.96 \\
MD/PAAc50 & 85.68 & 60.14 \\
MD/PAAc75 & 83.71 & 58.86 \\
\hline
\end{tabular}

The gel content of MD/PAAc at different radiation doses and MD contents is shown in Figure 6. The gel content of PAAc was as high as $88.65 \%$, with a dense three-dimensional network. However, as the MD content was increased from 0.1 to $0.5 \mathrm{wt} \%$, the gel content significantly decreased at $25 \mathrm{kGy}$ : the gel content for the $0.1,0.25$, and $0.5 \mathrm{wt} \% \mathrm{MD}$ containing samples was $82.58 \%, 71.33 \%$, and $53.06 \%$, respectively, as shown in Figure 3(b). The gel content of the only dried MD/PAAc was $64.29 \%$, indicating no cross-linking. The MD/PAAc samples exposed to increased radiation dose at 25, 50, and $75 \mathrm{kGy}$ had significantly lower gel contents of $49.38 \%, 40.71 \%$, and $29.54 \%$, respectively, as shown in Figure 3(a). This result suggests that the crystallinity of MD increased with increased radiation dose, as the samples were kept at room temperature for a long period of time during the irradiation process. 
(a)

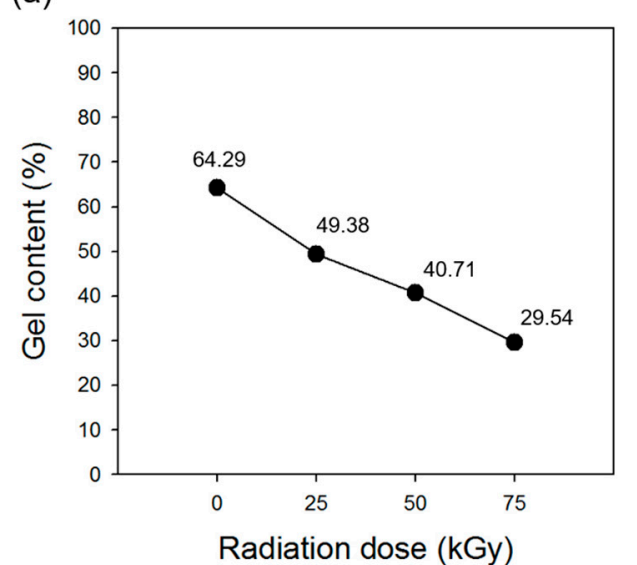

(b)

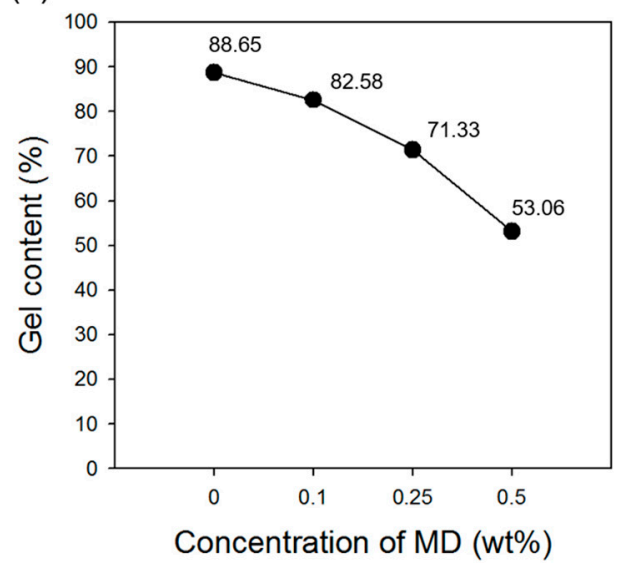

(a)

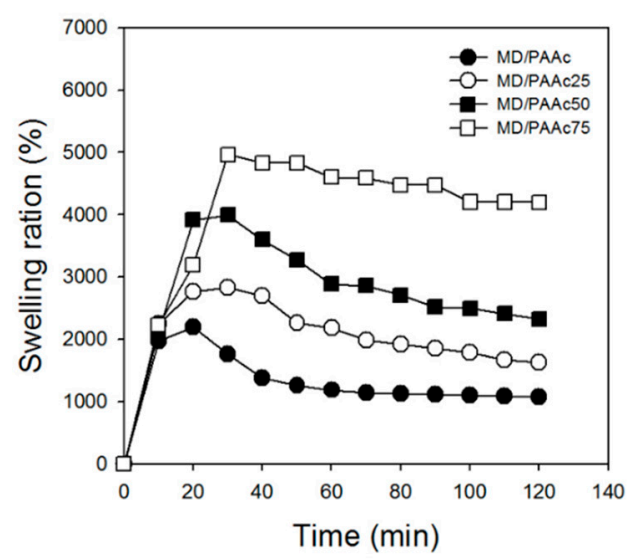

(b)

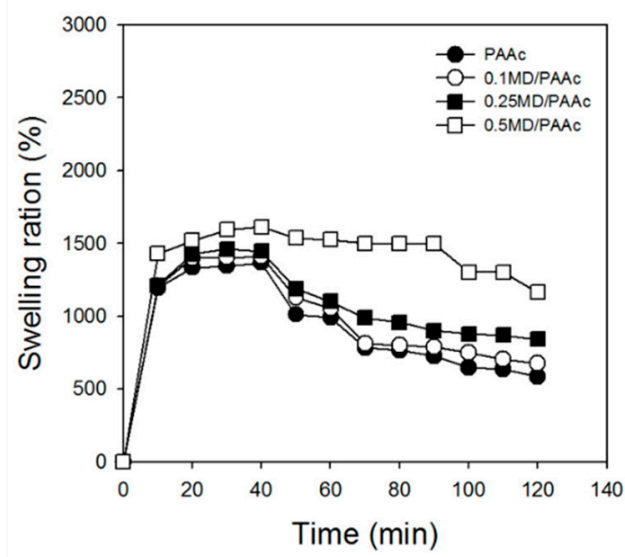

Figure 7. Swelling ratio of MD containing PAAc hydrogel films: (a) MD containing PAAc hydrogel films with different contents of $\operatorname{MD}(0,0.1,0.25$, and $0.5 \mathrm{wt} \%)$ and radiation dose of $25 \mathrm{kGy}$, (b) $1 \mathrm{wt} \%$ MD containing PAAc hydrogel films with different radiation doses $(25,50$, and $75 \mathrm{kGy}$ ).

Figure 6. Gel content of MD containing PAAc hydrogel films: (a) $1 w t \%$ MD containing PAAc hydrogel films with different radiation doses (25, 50, and $75 \mathrm{kGy})$, (b) MD containing PAAc hydrogel films with different contents of $\mathrm{MD}(0,0.1,0.25$, and $0.5 \mathrm{wt} \%)$ and radiation dose of $25 \mathrm{kGy}$.

Figure 7(a) shows that the swelling degree of MD/PAAc increased with an increase in MD content, as the porous three-dimensional networks were affected by MD incorporation. While the swelling degree of MD/PAAc 25 was $2,829 \%$, the MD/PAAc75 sample showed a swelling 
1 of $4,963 \%$. This suggests that MD/PAAc exhibits increased gel content with increasing

2 radiation dose. However, after $40 \mathrm{~min}$, the swelling degree decreased due to the destruction of

3 the hydrogel structure by the crystalline nature of MD.

(a)

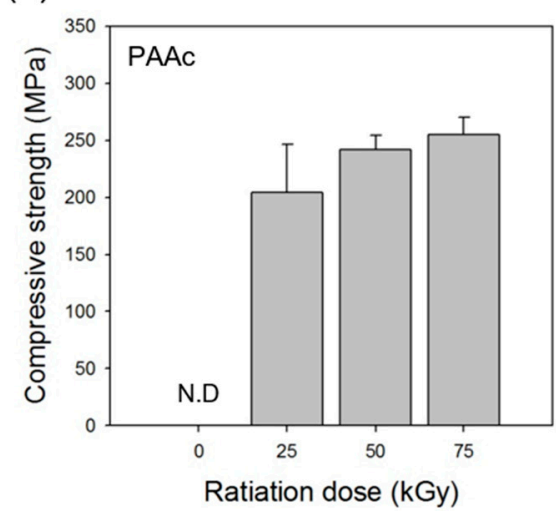

(c)

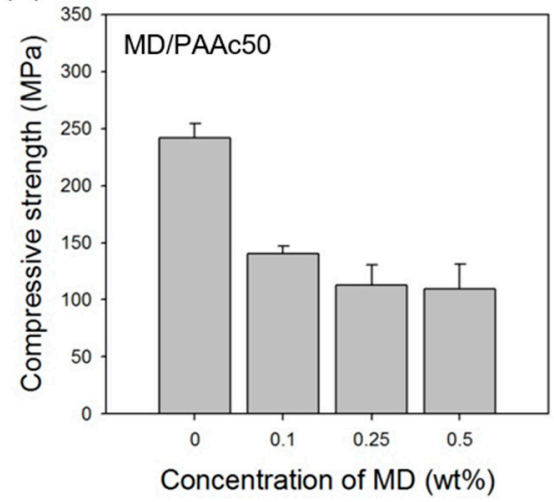

(b)

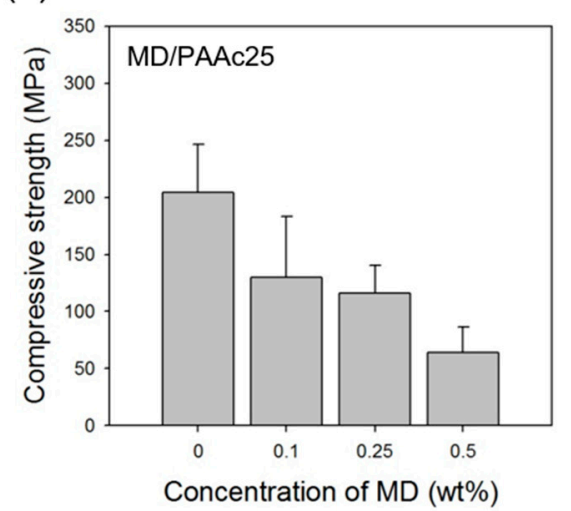

(d)

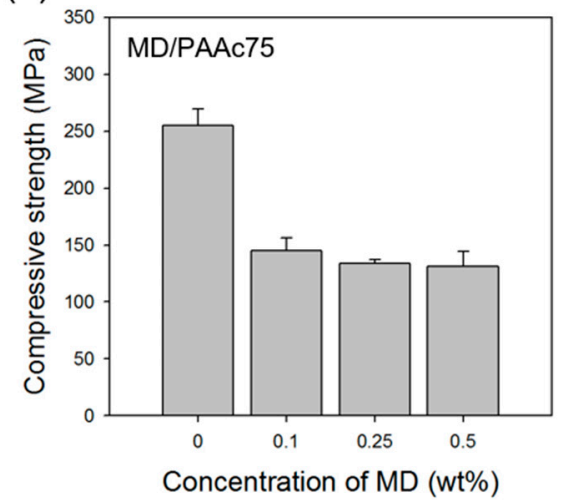

Figure 8. Compressive strength of MD containing PAAc hydrogel films: (a) $7 \mathrm{wt} \%$ PAAc hydrogel films with different radiation doses at $0,25,50$, and $75 \mathrm{kGy}$, (b) MD containing PAAc hydrogel films with different contents of $\mathrm{MD}(0,0.1,0.25$, and $0.5 \mathrm{wt} \%)$ and radiation dose at $25 \mathrm{kGy}$. (c) MD containing PAAc hydrogel films with different contents of MD $(0,0.1,0.25$, and $0.5 \mathrm{wt} \%$ ) and radiation dose at $50 \mathrm{kGy}$. (d) MD containing PAAc hydrogel films with different contents of $\mathrm{MD}(0,0.1,0.25$, and $0.5 \mathrm{wt} \%)$ and radiation dose at $75 \mathrm{kGy}$. (N.D = not detected)

Figure 8 shows the compressive strength of PAAc and MD/PAAc for different radiation doses and MD contents. In this study, a 50\% compression was chosen for the compressive strength of the $\beta$-glucan hydrogel. The compressive strength of PAAc was found to increase with the radiation dose at $25 \mathrm{kGy}(204.08 \pm 42.78 \mathrm{MPa}), 50 \mathrm{kGy}(242.17 \pm 12.01 \mathrm{MPa})$, and $75 \mathrm{kGy}(254.89 \pm 15.02 \mathrm{MPa})$, because of the larger degree of cross-linking in the hydrogels. 
1 At $25 \mathrm{kGy}$, the compressive strength of $0.1 \mathrm{MD} / \mathrm{PAAc} 25$ was $130.24 \mathrm{MPa}( \pm 53.16 \mathrm{MPa})$, while that of $0.5 \mathrm{MD} / \mathrm{PAAc} 25$ was $63.72 \mathrm{MPa}( \pm 22.86 \mathrm{MPa})$, indicating a decrease of approximately $60 \mathrm{MPa}$. The same trend in compressive strength was observed at the other radiation doses.

(a)

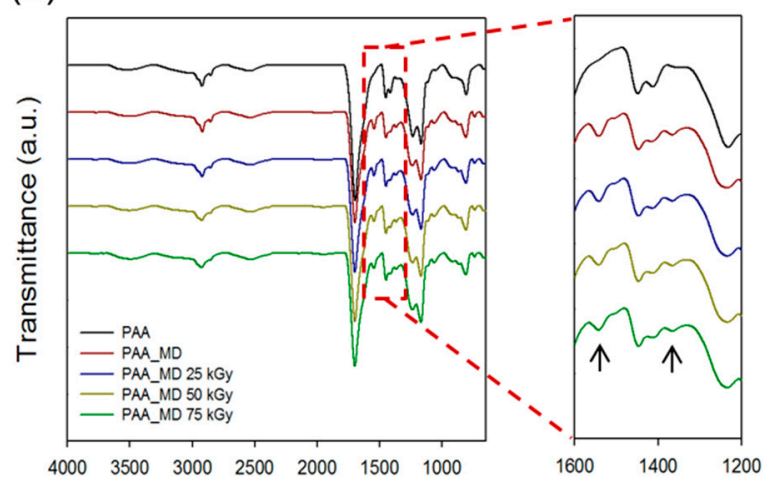

Wavenumber $\left(\mathrm{cm}^{-1}\right)$ (b)

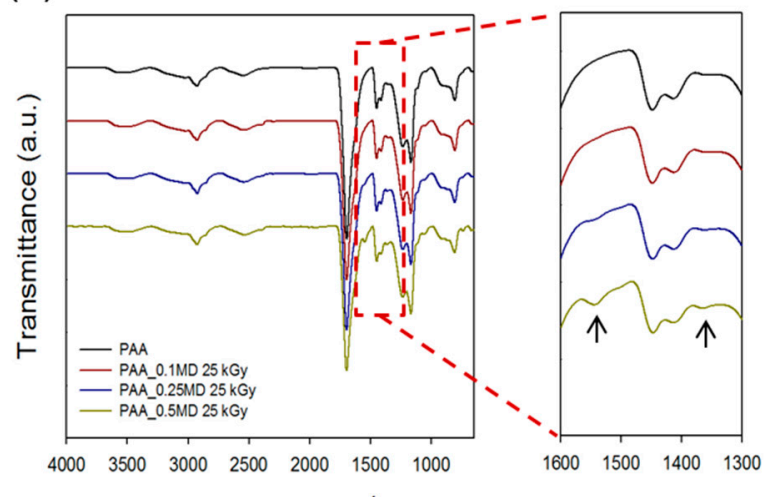

Wavenumber $\left(\mathrm{cm}^{-1}\right)$

Figure 9. Chemical properties of MD containing PAAc hydrogel films using ATRFTIR: (a) MD containing PAAc hydrogel films with different contents of MD (0, 0.1, 0.25 , and $0.5 \mathrm{wt} \%$ ) and radiation dose at $25 \mathrm{kGy}$, (b) $1 \mathrm{wt} \% \mathrm{MD}$ containing PAAc hydrogel films with different radiation doses $(0,25,50$, and $75 \mathrm{kGy})$.

Chemical characterization of the MD/PAAc samples was carried out using ATR-FTIR, and

the results are shown in Figure 9. The presence of PAAc was confirmed by - $\mathrm{COOH}$ (carboxylic acid group) and $-\mathrm{OH}$ (hydroxyl group) stretching vibrations at $1700 \mathrm{~cm}^{-1}$ and $3400 \mathrm{~cm}^{-1}$, respectively $[14,23]$. New peaks from the nitrite group of MD/PAAc were observed at 1363 $\mathrm{cm}^{-1}$ and $1541 \mathrm{~cm}^{-1}$ due to the presence of MD [24]. The peak intensity of the nitrite group increased with the MD concentration. In contrast, for MD/PAAc, there was no change in the intensity of the nitrite peak with an increase in the radiation dose from 25 to $75 \mathrm{kGy}$. 


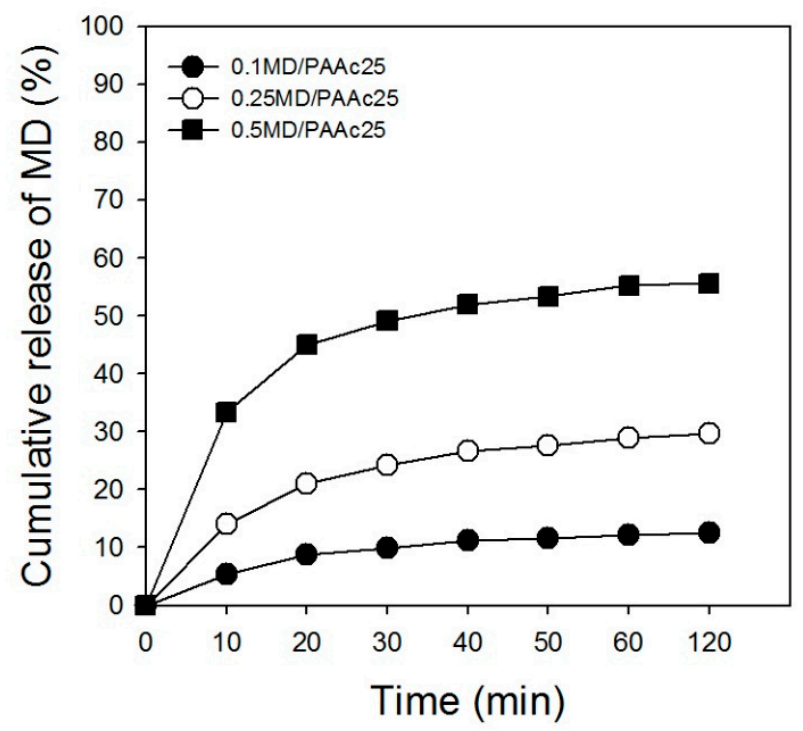

2 Figure 10. Drug release profile of MD containing PAAc hydrogel films.

4 The MD/PAAc hydrogels were dried at room temperature. The drug release was determined

5 by placing it in PBS ( $\mathrm{pH}$ 7.4). The release of MD was determined at various times by UV 6 spectroscopy. The absorbance was recorded at $319 \mathrm{~nm}$. The MD drug release profiles from the

$7 \quad$ PAAc hydrogels were investigated and are shown in Figure 10. As shown in Figure10, the drug 8 release confirmed that MD was slowly released without any initial burst. The drug was 9 consistently released from the PAA hydrogel (0.5MD/PAAc25), reaching $60 \%$ at 10 approximately $60 \mathrm{~min}$ in PBS. However, $0.1 \mathrm{MD} / \mathrm{PAAc}$ exhibited a release of approximately $10 \%$ at approximately $60 \mathrm{~min}$ in PBS.

\section{Conclusion}

14 In this study, MD containing PAA hydrogel films were synthesized by mixing various 15 quantities of MD and PAA, followed by $\gamma$-irradiation at different doses. The physical, chemical, and thermal properties of the MD/PAA samples were observed and characterized. When the 
1 fabricated $0.5 \mathrm{MD} / \mathrm{PAA} 25$ was exposed to $\gamma$-irradiation, the gel content was significantly

2 decreased as compared to that for MD/PAA. The presence of MD in MD/PAA was confirmed

3 by the observation of nitrite group peaks at $1363 \mathrm{~cm}^{-1}$ and $1541 \mathrm{~cm}^{-1}$, with an increase in peak

4 intensity with the MD content. In addition, the thermal properties of MD/PAA degraded with

5 an increase in the radiation dose and MD content. After $50 \mathrm{~min}$, the cumulative release of

$60.5 \mathrm{MD} / \mathrm{PAA}$ was more than $50 \%$, whereas that of $0.1 \mathrm{MD} / \mathrm{PAA}$ was $10 \%$. Therefore, MD/PAA

7 could be a viable candidate for a drug delivery carrier, with radiation-based techniques.

8

9

\section{Acknowledgments:}

This work was supported by INNOPOLIS foundation grant funded by the Ministry of Science and ICT (Information \& Communication Technology) and Future Planning, Ko rea government.

\section{References}

1. Francis, S.; Kumar, M.; Varshney, L. Radiation synthesis of superabsorbent poly(acrylic acid)-carrageenan hydrogels. Radiat. Phys. Chem. 2004, 69, 481-486.

2. Jabbari, E.; Nozari, S. Swelling behavior of acrylic acid hydrogels prepared by cradiation crosslinking of polyacrylic acid in aqueous solution. Eur. Polym. J. 2000, 36 , 2685-2692.

3. Broom, N.D.; Oloyede, A. The importance of physicochemical swelling in cartilage illustrated with a model hydrogel system. Biomaterials 1998, 19, 1179-1188.

4. Scotchford, C.A.; Cascone, M.G.; Downes, S.; Giusti, P. Osteoblast responses to collagen-PVA bioartificial polymers in vitro: the effects of cross-linking method and collagen content. Biomaterials 1998, 19, 1-11.

5. Yasin, Y.; Hassan, S. Synthesis of radiation crosslinked poly(acrylic acid) in the presence of phenyltriethoxysilane. Radiat. Phys. Chem. 2014, 97, 292-297.

6. Ulanski, P.; Rosiak, J.M. Synthesis of hydrogels by irradiation of polymers in aqueous solution. Radiat. Phys. Chem. 1999, 55, 139-151. 
7. Qi, X.; Hu, X.; Wei, W.; Yu, H.; Li, J.; Zhang, J.; Dong, W. Investigation of salecan/poly(vinyl alcohol) hydrogels prepared by freeze/thaw method. Carbohyd. polym. 2015, 118, 60-69.

8. Huang,X.; Zhang, Y.; Zhang, X.; Xu, L.; Chen, X.; Wei, S. Influence of radiation crosslinked carboxymethyl-chitosan/gelatin hydrogel on cutaneous wound healing. Mat. Sci. Eng. C. 2013, 33, 4816-4824.

9. Demetera, M.; Virgolicib, M.; Vanceaa, C.; Scarisoreanua, A.; Kayad, M.G.A.; Meltzerc, V. Network structure studies on $\gamma$-irradiated collagen-PVP superabsorbent hydrogels. Radiat. Phys. Chem. 2017, 131, 51-59.

10. Fekete, T.; Borsa, J.; Takacs, E.; Wojnarovits, L. Synthesis of cellulose derivative based superabsorbent hydrogels by radiation induced crosslinking. Cellulose 2014, 21 , 4157-4165.

11. Al-qudah, Y.H.F;Mahmoud, G.A.; Khalek, M.A.A. Radiation crosslinked poly (vinyl alcohol)/acrylic acid copolymer for removal of heavy metal ions from aqueous solution. J. Radiat. Res. Appl. Sci. 2014, 7, 135-145.

12. Nikolic, V.M.; Krkljes, A.; Popovic, Z.K.; Lausevic, Z.V.; Miljanic, S.S. On the use of gamma irradiation crosslinked PVA membranes in hydrogel fuel cells. Electrochem. Commun. 2007, 9, 2661-2665.

13. Yanga, J.M.; Sua, W.Y.; Leub, T.L.; Yang, M.C. Evaluation of chitosan/PVA blended hydrogel membranes. J. Membrane. Sci. 2004, 236, 39-51.

14. Singh, B.; Chauhan, N.; Kumar, S. Radiation crosslinked psyllium and polyacrylic acid based hydrogels for use in colon specific drug delivery. Carbohyd. Polym. 2008, 73 446-455.

15. Nho, Y.C.; Park, J.S.; Shin, J.W.; Lim, Y.M.; Jeong, S.I.; Shin, Y.M.; Gwon, H.J. Poly(acrylic acid)/polyethylene glycol hygrogel prepared by using gamma-ray irradiation for mucosa adhesion. J. Korean. Phys. Soc. 2015, 66, 17-21.

16. El-Rehim, H.A.A.; Swilem, A.E.; Klingner, A.; Hegazy, E.A.; Hamed, A.A. Developing the potential ophthalmic applications of pilocarpine entrapped into polyvinylpyrrolidone-poly(acrylic acid) nanogel dispersions prepared by $\gamma$ radiation. Biomacromolecules 2013, 14, 668-698.

17. Nho, Y.C.; Park, J.S.; Lim, Y.M. Preparation of poly(acrylic acid) hydrogel by radiation crosslinking and its application for mucoadhesives. Polymers 2014, 6, 890898.

18. Vasi, A.M.; Popa, M.I.; Tanase, E.C.; Butnaru, M.; Verestiuc, L. Poly(acrylic acid)poly(ethylene glycol) nanoparticles designed for ophthalmic drug delivery. J. Pham. Sci-US. 2014, 103, 676-686.

19. Lee, M.A. Antimicrobial Resistance Helicobacter pylori. Korean J Clin Microbiol. 2001, 4, 73-77.

20. Salahuddin, A.; Agarwal, S.M.; Avecilla, F.; Azam, A. Metronidazole thiosalicylate 
conjugates: synthesis, crystal structure, docking studies and antiamoebic activity. Bioorg. Med. Chem. Lett. 2012, 22, 5694-5699.

21. Martino, P.D.; Censi, R.; Malaj, L.; Capsoni, D.; Massarotti, V.; Martelli, S. Influence of solvent and crystallization method on the crystal habit of metronidazole. Cryst. Res. Technol. 2007, 42, 800-806.

22. de Souza, N.A.B.; Medeiros, A.C.D.; Santos, A.F.O.; Macedo, R.O. Thermal stability of metronidazole drug and tablets. J. Therm. Anal. Calorim. 2003, 72, 535-538.

23. Singh, R.; Maity, S.; Sa, B. Effect of ionic crosslink on the release of metronidazole from partially carboxymethylated guar gum tablet. Carbohyd. Polym. 2014, 106, 414421.

24. Ramukutty, S.; Ramachandran, E. Crystal growth by solvent evaporation and characterization of metronidazole. J. Cryst. Growth. 2012, 351, 47-50. 